\title{
Etiology of Hydronephrosis in adults and children: Ultrasonographic Assessment in 233 patients
}

\author{
Sultan Abdulwadoud Alshoabi ${ }^{1}$, Dahhan Saleh Alhamodi ${ }^{2}$, \\ Mohammed Ali Alhammadi ${ }^{3}$, Abdullah Fahad Alshamrani ${ }^{4}$
}

\begin{abstract}
Objectives: Hydronephrosis $(\mathrm{HN})$ is dilatation of the collecting system of the kidney due to obstruction of urine outflow. This study intended firstly, to investigate the efficacy of ultrasound (US) imaging to determine the cause of $\mathrm{HN}$, and secondly, to list the causes of HN.

Methods: In this retrospective study, 233 patients with $\mathrm{HN}$ were scanned to determine the cause of the $\mathrm{HN}$ in the period from $1^{\text {st }}$ January 2016 to $31^{\text {st }}$ October 2017. Categorical results were written as frequencies and percentages.

Results: Out of $233,91.41 \%$ were adults and $8.58 \%$ were children $(P<0.001), 66.10 \%$ were male and $33.90 \%$ were female $(P<0.001)$. In $55.36 \%$, HN was in the right kidney and $44.64 \%$ was in the left $(P=0.116)$. Exactly $58 \%$ of patients were suffering from grade- $2,21.5 \%$ grade- $3,11.6 \%$ grade- 1 , and $8.2 \%$ grade- $4 \mathrm{HN}$. US imaging can determine the cause of $\mathrm{HN}$ in $70.4 \%$ of patients. Kidney or ureteric calculi were the cause of $\mathrm{HN}$ in $54.1 \%$ of cases, reflux was in $7.3 \%$, and pelviureteric junction (PUJ) stenosis was in $3.9 \%$. In cases of calculi induced $\mathrm{HN}, 25.3 \%$ of the calculi were in the vesicoureteric junction (VUJ), $21.5 \%$ were in the renal pelvis, $6.4 \%$ were in the PUJ or upper ureter, and only $0.9 \%$ were in the middle ureter.

Conclusion: Ultrasound imaging can determine the cause of $\mathrm{HN}$ in more than two thirds of patients. Calculi are the most common cause of $\mathrm{HN}$ even in children and are most common in the VUJ.
\end{abstract}

KEYWORDS: Etiology; Hydronephrosis; Calculi; Pregnancy-induced hydronephrosis; Ultrasound imaging.

\section{Abbreviations:}

HN: Hydronephrosis, US: Ultrasound, PUJ: Pelviureteric Junction,

VUJ: Vesicoureteric Junction, SFU: Society of Fetal Urology,

MHz: Megahertz, SPSS: Statistical Package for the Social sciences,

IBM: International Business Machines, NY: New York, Cl: confidence interval.

doi: https://doi.org/10.12669/pjms.37.5.3951

How to cite this:

Alshoabi SA, Alhamodi DS, Alhammadi MA, Alshamrani AF. Etiology of Hydronephrosis in adults and children: Ultrasonographic Assessment in 233 patients. Pak J Med Sci. 2021;37(5):1326-1330. doi: https://doi.org/10.12669/pjms.37.5.3951

This is an Open Access article distributed under the terms of the Creative Commons Attribution License (http://creativecommons.org/licenses/by/3.0), which permits unrestricted use, distribution, and reproduction in any medium, provided the original work is properly cited.

\section{INTRODUCTION}

\section{Correspondence:}

Sultan Abdulwadoud Alshoabi, Associate Professor of Radiology,

Department of Diagnostic Radiology Technology,

College of Applied Medical Sciences,

Taibah University, Almadinah Almunawarah,

Postal Code: 42312,

Kingdom of Saudi Arabia.

E-mail: alshoabisultan@yahoo.com

* Received for Publication:

* Accepted for Publication:
November 26, 2020

April 28, 2021

Pak J Med Sci September - October 2021

Hydronephrosis (HN) is dilatation of the renal collecting system of the kidney due to obstruction of urine outflow in any part of the urinary tract. It can present solely or together with dilatation of the ureter in an entity called hydroureternephrosis. $\mathrm{HN}$ can present as unilateral or bilateral, acute or chronic at any age. ${ }^{1}$

According to the Society of Fetal Urology (SFU) classification system, $\mathrm{HN}$ is classified into four grades; Grade-1; dilatation of the renal pelvis only. Grade-2; dilatation of the renal pelvis and 
major calyces. Grade-3; dilatation of the renal pelvis and major and minor calyces. Grade-4; dilatation of the renal pelvis and all calyces with thinning of the renal parenchyma. The SFU classification system is used also in adults. ${ }^{2}$ This classification system has good intra observer and interobserver reliability and is recommended for assessment of neonatal $\mathrm{HN}^{3}{ }^{3}$

The most common reported causes of $\mathrm{HN}$ are kidney or ureteric calculi, pregnancy, pelviureteric junction (PUJ) stenosis or bladder outlet obstruction. ${ }^{4}$ Ultrasound (US) imaging is commonly used, universally available, noninvasive and radiation free imaging modality. It is highly valuable in diagnosing and grading of $\mathrm{HN} .{ }^{5}$

This study was designed to investigate the efficacy of US in determining the cause of $\mathrm{HN}$ which is a common medical problem in all age groups and the detection of the cause of $\mathrm{HN}$ is a critical point for planning of the management. Moreover, the study was carried out to examine the causes of $\mathrm{HN}$ in adults and children due to lack of enough similar previous studies about causes of $\mathrm{HN}$ in adults and children which is a common and important topic and many previous studies were concentrated only on prenatal and neonatal HN. This work will be beneficial for ultrasonographists, radiologists, urologists and emergency practitioners who are usually interested in detecting the cause of $\mathrm{HN}$ as a frequent and important problem corresponds to their daily work.

This study also elucidate the distribution of HN in the right and left kidneys and in male and female gender and explained the cause of predilection of $\mathrm{HN}$ to right side in female.

\section{METHODS}

This cross-sectional retrospective study involved 233 patients who underwent abdominal US imaging and diagnosed with $\mathrm{HN}$ at the US unit of Amran hospital in Yemen during the period from $1^{\text {st }}$ January 2016 to $31^{\text {st }}$ October 2017. This study involved both adults and children. Exclusion criteria include prenatal $\mathrm{HN}$ because a lot of previous studies satisfy this topic.

Procedure: All patients were scanned by the same radiologist who has eight years of experience in abdominal ultrasonography. A $3.5 \mathrm{MHz}$ curved transducer of Medison, Sono ex-model six color Doppler machine was used in scanning of all patients. Each patient was scanned in supine and oblique positions to demonstrate and grading $\mathrm{HN}$. Each kidney was examined in longitudinal and transverse sections with an examination of the whole ureter and urinary bladder to demonstrate the cause of HN.

Patients were scanned by the same highly experienced radiologist following the protocol of ultrasound imaging of the kidneys.

Statistical Analysis: The collected data were analyzed using the statistical package for social sciences (SPSS), IMB, version 23 for windows (Armonk, NY: IBM Corp. 2015). Chisquare test was used to compare urinary calculi in gender and side. $P$ value was assumed to be significant when $<0.05$. Cross tabulation was used to analyze relationship between gender and side distribution of urinary calculi. Results were reported as frequencies and percentages in categorical data.

Ethical Approval: Institutional ethical approval was obtained for this study. Confidentiality of the patients was assured during and after this study.

\section{RESULTS}

This study involved 233 patients who underwent abdominal US imaging and diagnosed as $\mathrm{HN}$. $91.41 \%$ were adults and $8.58 \%$ were children, $66.10 \%$ were male and $33.90 \%$ were female. $\mathrm{HN}$ was unilateral in $88.85 \%$ and bilateral in $11.5 \%$. $\mathrm{HN}$ was in the right kidney in $55.36 \%$ and $44.64 \%$ was in the left (Table-I).

Table-II shows that $58 \%$ of patients were suffering from mild (Grade-2) HN, 21.5\% moderate (Grade-3), 11.6\% minimal (Grade-1), and 8.2\% severe (Grade-4) HN (Fig.1).

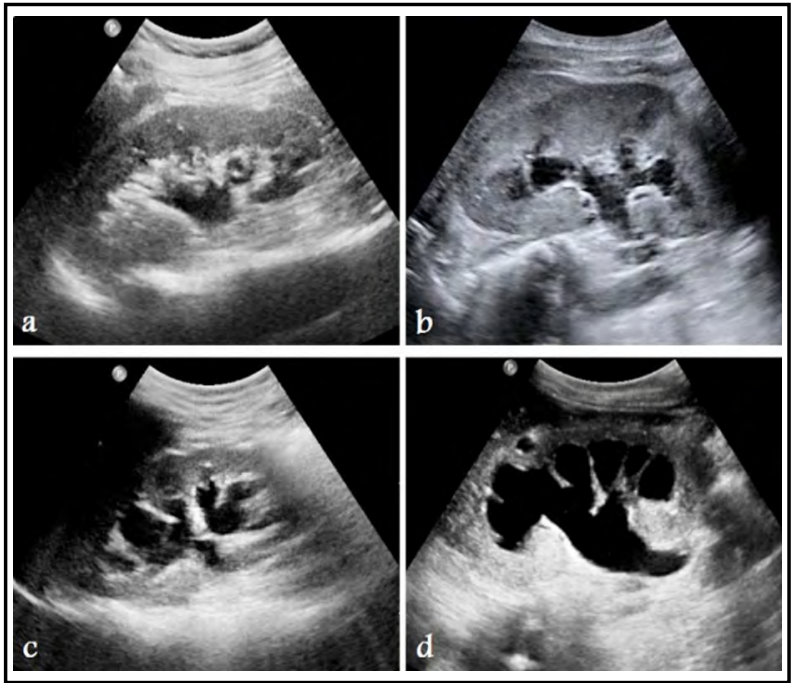

Fig.1: Ultrasound images of right kidney of different patients shows a) grade- 1, b) grade- 2 , c) grade- 3 , and d) grade- 4 hydronephrosis according to SFU grading system. 
Table-I: Age, sex and side groups of hydronephrosis.

\begin{tabular}{llccc}
\hline Variables & Categories & Numbers & Percentage & P-value \\
\hline \multirow{3}{*}{ Age } & Adult & 213 & 91.41 & \\
& Child & 20 & 8.58 & $<0.001$ \\
& Total & 233 & $100 \%$ & \\
Sex & Male & 154 & 66.10 & $<0.001$ \\
& Female & 79 & 33.90 & \\
\multirow{3}{*}{ Kidney } & Total & 233 & $100 \%$ & $<0.001$ \\
& Unilateral & 207 & 88.85 & \\
& Bilateral & 26 & 11.15 & \\
\multirow{3}{*}{ Side } & Total & 233 & $100 \%$ & 0.116 \\
& Right & 129 & 55.36 & 44.64 \\
\hline
\end{tabular}

Table shows significance association between hydronephrosis with adults and male gender $(\mathrm{P}<0.001)$,

but no significant association between hydronephrosis and any side $(\mathrm{P}=0.116)$.

Ultrasound imaging can determine the cause of $\mathrm{HN}$ in $70.4 \%$ of patients with $\mathrm{HN}$. Kidney or ureteric calculi was the cause of $\mathrm{HN}$ in $54.1 \%$ of cases, $7.3 \%$ of cases were reflux HN, PUJ stenosis was the cause in $3.9 \%$, and residual $\mathrm{HN}$ was determined in $1.7 \%$ of patients (Table-III). Regarding causes in children, calculi were the cause in $30 \%$ of cases, PUJ stenosis in $20 \%$, reflux $\mathrm{HN}$ in $15 \%$, residual in $5 \%$, and $25 \%$ with no determined cause (Table-IV).

Table-II: Grades of hydronephrosis.

\begin{tabular}{lcc}
\hline Categories & Numbers & Percentage \\
\hline Grade-1 & 27 & 11.6 \\
Grade-2 & 137 & 58.8 \\
Grade-3 & 50 & 21.5 \\
Grade-4 & 19 & 8.2 \\
\hline Total & 233 & 100 \\
\hline
\end{tabular}

Table reveals that grade- 2 hydronephrosis was the most common then grade-3.

Grade-1 (Mild): Dilatation of the renal pelvis only. Grade-2 (Mild): Grade-1+ dilatation of major calyces. Grade-3 (Moderate): Grade-2+ dilatation of all calyces.

Grade-4 (Severe): Grade-3+ thinning of the renal parenchyma.
In cases of calculi induced $\mathrm{HN}, 25.3 \%$ of calculi were in the vesicoureteric junction (VUJ) or distal part of ureter, $21.5 \%$ were in the renal pelvis, $6.4 \%$ were in the PUJ or upper ureter, and only $0.9 \%$ were in the middle ureteric part (Table-V).

The cross-tabulation test between sex and side of $\mathrm{HN}$ shows predilection of $\mathrm{HN}$ to the right side only in female but not statistically significant $(p=0.072)$, (Odds ratio $=0.832),(95 \%$ confidence interval (CI) 0.666-1.054), (Table-VI).

Table-III: Causes of hydronephrosis in all patients.

\begin{tabular}{lcc}
\hline Categories & Numbers & Percentage \\
\hline Calculi & 126 & 54.1 \\
Reflux & 17 & 7.3 \\
PUJ stenosis & 9 & 3.9 \\
Pregnancy & 8 & 3.4 \\
Residual & 4 & 1.7 \\
Not determined & 69 & 29.6 \\
\hline Total & 233 & 100 \\
\hline
\end{tabular}

Table reveals that ultrasound can detect the cause of hydronephrosis in $164(70.38 \%)$ of cases of hydronephrosis and calculi were the cause in 126 $(54.10 \%)$ of patients. 
Table-IV: Causes of hydronephrosis in children.

\begin{tabular}{lcc}
\hline Categories & Numbers & Percentage \\
\hline Calculi & 6 & 30 \\
PUJ stenosis & 4 & 20 \\
Reflux & 3 & 15 \\
Residual & 1 & 5 \\
Not determined & 5 & 25 \\
\hline Total & 20 & 100 \\
\hline
\end{tabular}

Table reveals that ultrasound can detect the cause of hydronephrosis in $164(70.38 \%)$ of cases of hydronephrosis and calculi were the cause in 126 $(54.10 \%)$ of patients.

\section{DISCUSSION}

$\mathrm{HN}$ is a widespread health problem worldwide that can be present at any age because of multiple causes. Determining the cause of $\mathrm{HN}$ is an essential when planning the treatment.

In a previous study by Riddell et al., the sensitivity of bedside US imaging to detect unilateral HN was $72-83 \% .^{6}$ In this study, we found that US imaging can determine the cause in $70.4 \%$ of all patients with HN. Another previous study by Moş et al. reported that transabdominal US imaging can identify $\mathrm{HN}$ in $88.94 \%$ and can identify ureteric calculi in nearly $73 \%$ of patients. ${ }^{7}$ Sternberg et al. reported that HN on US imaging has a $77 \%$ positive predictive value for diagnosis of ureteric calcui with $71 \%$ negative predictive value. $^{8}$

Table-V: Common sites of detected calculi in cases of hydronephrosis.

\begin{tabular}{lcc}
\hline Categories & Numbers & Percentage \\
\hline Renal pelvis & 50 & 21.5 \\
Upper ureter & 15 & 6.4 \\
Mid ureter & 2 & .9 \\
Lower ureter & 59 & 25.3 \\
Other causes & 38 & 16.3 \\
Not determined & 69 & 29.6 \\
\hline Total & 233 & 100 \\
\hline
\end{tabular}

Table reveals that calculi were common in distal part of ureter, then renal pelvis, followed by upper ureter.
Table-VI: Cross-tabulation test between sex and side of hydronephrosis.

\begin{tabular}{lccc}
\hline Categories & Right & Left & \\
\hline Male & $80(51.9 \%)$ & $74(48.1 \%)$ & 154 \\
Female & $49(62 \%)$ & $30(38 \%)$ & 79 \\
\hline Total & $129(55.4 \%)$ & $104(44.6 \%)$ & 233 \\
\hline
\end{tabular}

Table reveals slight predilection of hydronephrosis to the right side only in female but not statistically significant $(\mathrm{p}=0.072)$.

In this study, we found that $\mathrm{HN}$ was more common in male than in female, mild (grade-2) $\mathrm{HN}$ was the most common and ureteric or kidney calculi were the most common cause even in children. These results were consistent with that of Nuraji and Hyseni., who reported that $\mathrm{HN}$ was more common in grade- 2 and in males with kidney and ureteric stones were the most common cause. ${ }^{4}$ These results are also consistent with a previous study by Abu-Ghazzeh and Abdu-Alro'f, who reported that calculi were the most common cause of obstructive $\mathrm{HN}$ and were most common in the VUJ. ${ }^{9}$

Another similar study by Hansen et al. reported that calculi were the most common cause of HN in adults. He reported that renal pelvic, PUJ and VUJ calculi can be detected by US. However, calculi in the ureter are difficult to be detected due to obscuration by bowel gases. ${ }^{10}$ This explains the low detection rate of ureteric calcui by US which reported in the results of this study. Calculi are the cause of $\mathrm{HN}$ in $54.1 \%$ of patients in the current study. This is consistent with another previous study by Alshoabi, who reported that calculi were the cause of $\mathrm{HN}$ in $60 \%$ of cases. ${ }^{11}$

This study showed predilection of HN to male gender. This predilection was explained by the results of a previous study by Ahmed et al. who reported that urinary tract calculi, which are the most common cause of $\mathrm{HN}$, are formed more common in males due to hormonal effects. ${ }^{12}$

The high prevalence of nephrolithiasis in males is attributed to the effect of sex hormones such as androgens on some lithogenic risk factors which increases excretion and deposition of calcium oxalate in the pelvicalyceal system and kidney stone formation. In addition, estrogen decreases excretion of urinary oxalate and contribute in nephrolithiasis. ${ }^{12}$ 
The current study revealed predilection of $\mathrm{HN}$ to the right side in female gender. This can be explained by that pregnancy-induced $\mathrm{HN}$ was the cause in $3.4 \%$ of cases and was reported more common on the right side. ${ }^{13}$

\section{CONCLUSION}

Ultrasound imaging is an effective method to diagnose hydronephrosis which is a very common medical problem predominantly in adults, more in male, and slightly predominate on the right side. Ultrasound imaging can determine the cause of hydronephrosis in more than two thirds of patients. Ureteric or kidney calculi were the most common cause of hydronephrosis followed by reflux. Pelviureteric junction stenosis and residual hydronephrosis were uncommon causes. Calculi were determined in vesicoureteric junction, then in the renal pelvis and upper ureteric part and rarely in the middle ureteric part.

Significant statement: This study focused on studying the ability of US imaging to determine the cause of $\mathrm{HN}$ which is a common medical problem worldwide. US is a widely available and safe medical imaging modality that can frequently determine the cause of $\mathrm{HN}$ and calculi are the most common determined cause. This data is highly valuable to ultrasonographists, radiologists, urologists and physicians who commonly using ultrasound imaging.

Conflicts of interest: The authors declare no conflicts of interest.

\section{Financial support: None}

\section{REFERENCES}

1. Ilgi M Sr, Bayar G, Abdullayev E, et al. Rare Causes of Hydronephrosis in Adults and Diagnosis Algorithm: Analysis of 100 Cases During 15 Years. Cureus. 2020;12(5):e8226. doi: 10.7759/cureus.8226

2. Onen A. Grading of Hydronephrosis: An Ongoing Challenge. Front Pediatr. 2020;8:458. doi: 10.3389/ fped.2020.00458

3. Choi YH, Cheon JE, Kim WS, Kim IO. Ultrasonography of hydronephrosis in the newborn: A practical review. Ultrasonography. 2016;35(3):198-211. doi: 10.14366/usg.15073

4. Nuraj P, Hyseni N. The Diagnosis of Obstructive Hydronephrosis with Color Doppler Ultrasound. Acta Inform Med. 2017;25(3):178-181. doi: 10.5455/ aim.2017.25.178-181
5. Rykkje A, Carlsen JF, Nielsen MB. Hand-Held Ultrasound Devices Compared with High-End Ultrasound Systems: A Systematic Review. Diagnostics (Basel). 2019;9(2):61. doi: 10.3390/diagnostics9020061

6. Riddell J, Case A, Wopat R, et al. Sensitivity of emergency bedside ultrasound to detect hydronephrosis in patients with computed tomography-proven stones. West J Emerg Med. 2014;15(1):96-100. doi: 10.5811/westjem.2013.9.15874

7. Moş C, Holt G, Iuhasz S, Moş D, Teodor I, Halbac M. The sensitivity of transabdominal ultrasound in the diagnosis of ureterolithiasis. Med Ultrason. 2010;12(3):188-197.

8. Sternberg KM, Pais VM Jr, Larson T, Han J, Hernandez $\mathrm{N}$, Eisner B. Is Hydronephrosis on Ultrasound Predictive of Ureterolithiasis in Patients with Renal Colic? J Urol. 2016;196(4):1149-1152. doi: 10.1016/j.juro.2016.04.076

9. Abu-Ghazzeh Y, Abdu-Alro'f S. The role of ultrasound in initial evaluation of renal colic. Saudi J Kidney Dis Transpl. 2000;11(2):186-190.

10. Hansen KL, Nielsen MB, Ewertsen C. Ultrasonography of the Kidney: A Pictorial Review. Diagnostics (Basel). 2015;6(1):2. doi: 10.3390/diagnostics6010002

11. Alshoabi SA. Association between grades of Hydronephrosis and detection of urinary stones by ultrasound imaging. Pak J Med Sci. 2018;34(4):955-958. doi: 10.12669 / pjms.344.14602

12. Ahmad S, Ansari TM, Shad MS. Prevalence of renal calculi; type, age and gender specific in Southern Punjab, Pakistan. Professional Med J. 2016;23:389-395.

13. Rajaei Isfahani $M$, Haghighat $M$. Measurable changes in hydronephrosis during pregnancy induced by positional changes: ultrasonic assessment and its diagnostic implication. Urol J. 2005;2(2):97-101.

\section{Authors' Contribution:}

SAA Prepared the manuscript and critically reviewed and approved the final draft and is responsible for the accuracy of the work.

DSA collected and organized data.

MAA interpreted data.

AFA revised and final approval of the manuscript.

Authors:

1. Sultan Abdulwadoud Alshoabi,

Department of Diagnostic Radiology Technology,

2. Dahhan Saleh Alhamodi,

Unit of Ultrasound Imaging,

Department of Radiology,

Amran Hospital, Amran, Republic of Yemen

3. Mohammed Ali Alhammadi,

Department of Radiology and Medical Imaging,

Prince Mohamad bin Abdulaziz Hospital, National Guard,

Almadinah Almunawarah,

Kingdom of Saudi Arabia.

4. Abdullah Fahad Alshamrani,

Department of Diagnostic Radiology Technology,

1,4: College of Applied Medical Sciences,

Taibah University,

Almadinah Almunawarah,

Kingdom of Saudi Arabia. 